\title{
Mössbauer spectroscopy and the understanding of the role of iron in neurodegeneration
}

\author{
A. Friedman ${ }^{1} \cdot$ J. Galazka-Friedman ${ }^{2}$
}

Published online: 17 July 2017

(C) The Author(s) 2017. This article is an open access publication

\begin{abstract}
The possible role of iron in neurodegeneration may be related to the oxidative stress, triggered by Fenton reaction. In this reaction hydroxyl free radical production is generated by divalent iron. Motor symptoms of Parkinson's disease depend on the destruction of substantia nigra $(\mathrm{SN})$. As the substantive questions were: 1 / what is the concentration of iron in the samples, $2 /$ what is the proportion of divalent vs. trivalent iron in the samples, and 3/ what is the iron-binding compound, it seemed appropriate to use Mössbauer spectroscopy to answer those questions. We found no difference in the concentration of total iron between PD and control, with the ratio of iron in PD vs. control being $1.00 \pm 0.13$. The divalent iron could not exceed $5 \%$ of the total iron. The main iron-binding compound in SN, both in PD and control is ferritin. Our further studies of ferritin in parkinsonian SN demonstrated a decrease, compared to control, of L-ferritin involved in the storage of iron within ferritin. This could allow an efflux of iron from the ferritin shell and an increase of nonferritin iron in PD SN, which was confirmed by us. Mössbauer studies in Alzheimer showed slightly higher concentration of iron in hippocampal cortex with significantly higher concentrations of $\mathrm{L}$ and $\mathrm{H}$ ferritins compared to control. In atypical parkinsonism, progressive supranuclear palsy, higher concentration of iron was found in globus pallidus and SN compared to control. Mössbauer spectroscopy may play crucial role in further studies of human neurodegeneration.
\end{abstract}

Keywords Mössbauer spectroscopy · Iron · Neurodegeneration

This article is part of the Topical Collection on Proceedings of the 3rd Mediterranean Conference on the Applications of the Mössbauer Effect (MECAME 2017), Jerusalem, Israel, 5-7 June 2017

Edited by Mira Ristic, Stjepko Krehula, Israel Nowik and Israel Felner

A. Friedman

andrzej.friedman@wum.edu.pl

1 Department of Neurology, Medical University of Warsaw, Kondratowicza 8, Warsaw, Poland

2 Faculty of Physics, Warsaw University of Technology, Koszykowa 67, Warsaw, Poland 


\section{Introduction}

Neurodegeneration is a process leading to death of nervous cells in the brain. As a result of neurodegeneration appear symptoms of neurological diseases such as Parkinson, Alzheimer and several others. Symptoms of the disease depend on the location of the process. Motor symptoms of Parkinson's disease (slowness of movements, muscular rigidity and rest tremor) are due to the destruction of substantia nigra, a small $(\sim 500 \mathrm{mg})$ structure located bilaterally deep in the brain stem (mesencephalon). Memory loss, which is the main symptom of Alzheimer disease depends on the lesion to hippocampus, being a part of the temporal lobe of the brain.

The cause of these processes is not fully understood but according to the present knowledge, various mechanisms could be involved. They include exogenous toxicity, inflammatory process, genetics, prion-like misfolded protein self-multiplication and iron-mediated oxidative stress.

Oxidative stress is related to over production of free radicals mostly via Fenton reaction, which depends on divalent iron: $\mathrm{Fe}^{2+}+\mathrm{H}_{2} \mathrm{O}_{2} \rightarrow \mathrm{Fe}^{3+}+\mathrm{OH}^{\bullet}+\mathrm{OH}^{-}$.

Therefore iron was intensively studied in human brain structures involved in neurodegeneration and the results of these works especially regarding substantia nigra and parkinsonism vary enormously. The history of the iron studies in PD was recently presented in a review paper [1].

\section{Wide spread of the results}

The first comparison of the concentration of iron in PD and control brain comes from a paper by Lhermitte et al who assessed iron in the autopsied parkinsonian and control brain using Perl staining, and declared no difference in the concentration of iron between parkinsonian and control SN together with an increase of iron in parkinsonian globus pallidus (another structure of human brain also involved in some neurodegenerations) [2]. This paper is often erroneously cited as the first description of an increase of the total iron concentration in Parkinson's disease substantia nigra.

The first study aimed directly to compare the concentrations of iron in parkinsonian and control substantia nigra was published long time afterword [3]. This author, who used Xray fluorescent spectrometry, assessed 11 parkinsonian and unknown number of control SN. All these brains were stored in formalin for very long time (control brains probably around 70 years). The only result given by this author was that the concentration of iron in PD samples was 2 times higher than in control. 20 years later several studies began to be published with wide range of the obtained results, some showing higher concentration of iron in parkinsonian SN, some showing no difference or even lower concentration in PD. These studies including the results of the assessment of iron concentration in control samples are shown in Table 1 and in PD in Table 2. It should be noted that the results differ by the factor of 10 (from 40 to $400 \mathrm{ng} / \mathrm{mg}$ wet tissue).

The study by Sofic et al., where spectrophotometry was used, is the only one which assessed separately divalent and trivalent iron [4]. In this study non only the concentration of total iron was found to be higher in PD than in control but also significantly higher concentration of trivalent iron in parkinsonian SN was detected. It is important to note that the absolute values of the concentration of iron in this study was significantly lower than in all other studies (see Tables 1 and 2). The method used in this work needs a pretreatment of 
Table 1 Concentration of iron in substantia nigra in normal human brains wet tissues

\begin{tabular}{llrl}
\hline Author (year) & Method & $\begin{array}{l}\text { No of } \\
\text { samples }\end{array}$ & $\begin{array}{l}\text { Iron concentration } \\
\text { (ng/mg) }\end{array}$ \\
\hline Hallgren and Sourander (1958) [18] & Colorimetry & 81 & $184.6 \pm 65.2$ \\
Sofic et al. (1988) [4] & Spectrophotometry & 8 & $48 \pm 8$ \\
Zecca and Swartz (1993) [19] & Total reflection X-ray fluorescence & 5 & $410 \pm 223$ \\
Griffiths and Crossman (1993) [20] & Atomic absorption & 6 & $140 \pm 13$ \\
Galazka-Friedman et al. (2012) [6] & Mössbauer spectroscopy & 29 & $177 \pm 14$ \\
\hline
\end{tabular}

Table 2 Concentration of iron in substantia nigra in parkinsonian wet tissue

\begin{tabular}{llcc}
\hline Author (year) & Method & $\begin{array}{l}\text { No of } \\
\text { samples }\end{array}$ & $\begin{array}{c}\text { Iron concentration } \\
\text { (ng/mg) }\end{array}$ \\
\hline Sofic et al. (1988) [4] & Spectrophotometry & 8 & $85 \pm 11$ \\
Griffiths and Crossman (1993) [20] & Atomic absorption & 6 & $281 \pm 22$ \\
Galazka-Friedman et al. (2012) [6] & Mössbauer spectroscopy & 17 & $177 \pm 18$ \\
\hline
\end{tabular}

samples with chloric acid and pepsin, which allows a destruction of iron storage protein the ferritin, and an efflux of iron from its shell.

None of these studies aimed to determine the iron binding compound in the brain structures measured.

\section{Mössbauer spectroscopy enters in the field}

As the wide range of the results of studies measuring concentration of iron in human brain samples was obviously related to methods used by scientists and as the assessment of divalent and trivalent iron could have major importance for understanding possible mechanisms of neurodegeneration, we decided to use the Mössbauer spectroscopy. We knew that the best laboratory in the world for the Mössbauer spectroscopy applied to biological samples was the laboratory headed by Professor Bauminger in Jerusalem. Our collaboration on this topic began with the first common paper published in 1994 [5] and has been continued up to now. Using Mössbauer spectroscopy we investigated several neurodegenerative processesParkinson's disease, atypical parkinsonism (progressive supranuclear palsy) and Alzheimer disease.

\section{Total iron in Parkinson's disease and control}

The results obtained by us with the use of Mössbauer spectroscopy on 29 control and 17 parkinsonian SN [6] demonstrated:

- there is no difference in the total concentration of iron in substantia nigra in PD (177 \pm 18) and control $(177 \pm 14) \mathrm{ng} / \mathrm{mg}$ wet tissue 
- the concentration of divalent iron cannot exceed $10 \%$ of the total iron both in PD and control

- the iron in substantia nigra is mostly ferritin-like iron

Analyzing the spectra obtained at $90 \mathrm{~K}$ we found a difference between PD and control, which concerned the shape of the spectra. The spectra from PD were more asymmetric than those from control SN [7]. This difference could be due to a different structure of the iron core of ferritin in PD and control SN.

The summary of our collaborative studies with Professor Bauminger was published in 2013 [8].

\section{Is there a difference in iron concentration between parkinsonian and control SN?}

If according to Mössbauer spectroscopy there is no difference in ferritin-like iron, and the molecular weight of ferritin is about $20 \mathrm{kDa}$ [9], next step was to determine the concentration of iron in SN after elimination of all molecules bigger than $10 \mathrm{kDa}$. We compared the concentrations of this iron in PD and control [10]. The concentration of this non-ferritin iron was significantly higher in PD $(135 \pm 10 \mathrm{ng} / \mathrm{g})$ than in control $(76 \pm 5 \mathrm{ng} / \mathrm{g})$. It is important to note that these concentrations are 1000 times smaller than the concentrations of total iron in SN. Such small concentration could not, of course, be detected by Mössbauer spectroscopy.

\section{What could be the cause of this higher concentration of non-ferritin iron in PD?}

As iron is kept in a safe form within the ferritin shell, the idea was that this higher concentration of non-ferritin iron could be related to the change in the structure of ferritin. Ferritin is a protein formed of $\mathrm{H}$ and $\mathrm{L}$ chains. The $\mathrm{H}$ chains are related to metabolism of iron with quick incorporation to the protein shell and quick efflux as needed for the intracellular reactions, and L chains respond for the safe storage of iron within this protein [11]. With the use of ELISA (enzyme-linked immunosorbent assay) we analyzed the structure of ferritin in PD and control SN, and also in the preclinical PD — the Incidental Lewy Bodies cases [12]. Our study has shown a significant decrease of the concentration of L ferritin in PD compared to control, which is seen already in the preclinical cases. This finding may suggest that the whole process starts with the lowering of the ability of ferritin to keep iron in a safe form within the ferritin shell. The possible role of iron in neurodegeneration was discussed elsewhere [13].

\section{Iron studies with the use of Mössbauer spectroscopy in other neurodegenerations-Alzheimer disease and progressive supranuclear palsy}

The structure mostly affected in AD is hippocampal cortex, which lesion leads to memory loss, the principal symptom of the disease. With the use of MS and in some cases atomic absorption we determined the concentration of iron in hippocampal cortex obtained from brains of humans with $\mathrm{AD}$ and controls. The total concentration of iron in $\mathrm{AD}$ hippocampus 
was significantly higher compared to control ( $66 \pm 13$ vs. $45 \pm 10 \mathrm{ng} / \mathrm{mg}$ wet tissue). It is important to note that the concentration of iron in this structure is significantly lower than the iron concentration in substantia nigra. We next analyzed the structure of ferritin in these samples and we found, contrary to PD, higher concentrations of both $\mathrm{H}$ and $\mathrm{L}$ ferritins in the disease compared to control [14]. This finding suggests a different mechanism of neurodegeneration probably related to inflammatory process with proliferation of glial cells rich in iron.

Progressive supranuclear palsy (PSP) is a form of neurodegeneration, which causes symptoms including parkinsonism, difficulties of eye movements and dementia. It is referred to as atypical parkinsonism. The destruction involves $\mathrm{SN}$ and other brain areas, like globus pallidus GP). We used MS to assess the concentration of total iron in SN and GP obtained at autopsies from brains of patients who died with the clinical and neuropathological diagnosis of PSP [15]. The study has shown higher concentrations of total iron compared to control both in SN ( $301 \pm 26$ vs. $188 \pm 22 \mathrm{ng} / \mathrm{mg}$ wet tissue $)$ and GP ( $257 \pm 19$ vs. 183 $\pm 22 \mathrm{ng} / \mathrm{mg}$ wet tissue). Nothing is known about the ferritin structure in PSP yet.

\section{Mössbauer spectroscopy and magnetic resonance imaging}

Magnetic resonance imaging relaxation times may reflect the concentration of iron, as it was shown in a study in which Professor Bauminger also participated [16]. We decided to compare relaxation times from different brain structures (SN, globus pallidus, and hippocampal cortex) in living patients with Parkinson's disease, atypical parkinsonism-progressive supranuclear palsy and controls with the concentration of iron measured by Mössbauer spectroscopy. The results of MS were taken from our previous published studies of brain samples of the same structures of patients with the same diagnoses and controls [17]. A perfect correlation between R1 (1/T1) time and the concentration of iron in brain samples was found, the coefficient of correlation being 0.945 . Concerning R2 (1/T2) the situation was more complicated. There was again a perfect correlation with iron for all structures (0.983) except SN in pathology (PD and PSP) not in control. The values for R2 for PD and PSP escaped from this correlation, and what was more surprising, to different directions. What could be the reason for this change in pathological SN remains to be elucidated.

\section{Conclusions}

Mössbauer spectroscopy was found to be an important tool for examination of human brain samples and allowed a better understanding of possible mechanisms of neurodegeneration. Its unique feature of giving the results without any destruction of the tissue, what allowed further studies of the same samples made Mössbauer spectroscopy extremely important for understanding of human brain diseases.

Open Access This article is distributed under the terms of the Creative Commons Attribution 4.0 International License (http://creativecommons.org/licenses/by/4.0/), which permits unrestricted use, distribution, and reproduction in any medium, provided you give appropriate credit to the original author(s) and the source, provide a link to the Creative Commons license, and indicate if changes were made.

\section{References}

1. Friedman, A., Galazka-Friedman, J.: The history of the research of iron in parkinsonian substantia nigra. J. Neural Transm. 119, 1507-1510 (2012) 
2. Lhermitte, J., Krauss, W.M., McAlpine, D.: On the occurrence of abnormal deposits of iron in the brain in parkinsonism with special reference to its localization. J. Neurol. Psychopathol. 5, 195-208 (1924)

3. Earle, K.M.: Studies on Parkinson's disease including X-ray fluorescent spectroscopy of formalin fixed brain tissue. J. Neuropathol. Exp. Neurol. 27, 1-13 (1968)

4. Sofic, E., Riederer, P., Heinsen, H., et al.: Increased iron (III) and total iron content in post mortem substantia nigra of parkinsonian brain. J. Neural Trans. 74, 199-205 (1988)

5. Bauminger, E.R., Barcikowska, M., Friedman, A., Gałązka-Friedman, J., Nowik, H.D.: Does iron play a role in Parkinson's disease? Hyperfine Interact. 91, 853-856 (1994)

6. Galazka-Friedman, J., Bauminger, E.R., Szlachta, K., Friedman, A.: The role of iron in neurodegeneration-Mössbauer spectroscopy, electron microscopy, enzyme-linked immunosorbent assay and neuroimaging studies. J. Phys. Condens. Matter 24, 244101(7pp) (2012). doi:10.1088/0953-8984/24/24/244106

7. Galazka-Friedman, J., Bauminger, E.R., Tymosz, T., Friedman, A.: Mössbauer spectroscopy, electron microscopy and electron diffraction studies of ferritin-like iron in human heart, liver and brain. Hyperfine Interact. (C) 3, 49-52 (1998)

8. Galazka-Friedman, J., Bauminger, E.R., Friedman, A.: Iron in neurodegeneration. In: Sharma, V.K., Klingelhöfer, G., Nishida, T. (eds.) Mössbauer Spectroscopy-Applications in Chemistry, Biology and Nanotechnology, pp. 324-332. Wiley, New York (2013)

9. Theil, E.C.: Ferritin: structure, gene regulation, and cellular function in animals, plants, and microorganisms. Annu. Rev. Biochem. 56, 289-315 (1987)

10. Wypijewska, A., Galazka-Friedman, J., Bauminger, E.R., Wszolek, Z.K., Schweitzer, K.J., Dickson, D.W., Jaklewicz, A., Elbaum, D., Friedman, A.: Iron and reactive oxygen species activity in parkinsonian substantia nigra. Park. Rel. Disord. 16, 329-333 (2010)

11. Harrison, P.M., Arosio, P.: The ferritins: molecular properties, iron storage function and cellular regulation. Biochim. Biophys. Acta 1275(3), 161-120 (1996)

12. Koziorowski, D., Friedman, A., Arosio, P., Santambrogio, P., Dziewulska, D.: ELISA reveals a difference in the structure of substantia nigra ferritin in Parkinson's disease and Incidental Lewy Body compared to control. Park Rel. Disord. 13, 214-218 (2007)

13. Friedman, A., Arosio, P., Finazzi, D., Koziorowski, D., Galazka-Friedman, J.: Ferritin as an important player in neurodegeneration. Park Rel. Disord. 17, 423-430 (2011)

14. Gałązka-Friedman, J., Bauminger, E.R., Szlachta, K., Koziorowski, D., Tomasiuk, R., Jaklewicz, A., Wszolek, Z.K., Dickson, D., Kaplinska, K., Friedman, A.: Iron in Alzheimer and control hippocampiMössbauer, atomic absorption and ELISA studies. Acta Phys. Pol. 119, 81-83 (2011)

15. Galazka-Friedman, J., Bauminger, E.R., Szlachta, K., Schweitzer, K., Wszolek, Z., Dickson, D., Friedman, A.: Mössbauer studies of pathological brain tissues affected by PSP disease. Acta Phys. Pol. 115, 431-433 (2009)

16. Vymazal, J., Brooks, R.A., Baumgarner, C., Tran, V., Katz, D., Bulte, J.W.M., Bauminger, E.R., Chiro, G.D.: The relation between brain iron and NMR relaxation times: an in vitro study. Magn. Reson. Med. 35, 56-61 (1996)

17. Kulinski, R., Bauminger, E.R., Friedman, A., Duda, P., Galazka-Friedman, J.: Iron in typical and atypical parkinsonism-Mössbauer spectroscopy and MRI studies. Hyperfine Interact. 237, 4 (2016). doi:10.1007/s10751-016-1234-4

18. Hallgren, B., Sourander, P.: The effect of age on the non-haemin iron in the human brain. J. Neurochem. 3, 41-51 (1958)

19. Zecca, L., Swartz, H.M.: Total and paramagnetic metals in human substantia nigra and its neuromelanin. J. Neural Trans. Park Dis. Dement. Sect. 5, 203-213 (1993)

20. Griffiths, P.D., Crossman, A.R.: Distribution of iron in the basal ganglia and neocortex in post mortem tissue in Parkinson's disease and Alzheimer's diseases. Dementia 4, 61-65 (1993) 